\title{
- atlas COMO MÉtodo PARA O DESIGN. O USO DO ATLAS E DOS CONCEITOS DE MONTAGEM COMO FERRAMENTA METODOLÓGICA PARA A PESQUISA VISUAL.
}

\section{THE ATLAS AS A METHOD FOR DESIGN: THE USE OF ATLAS AND ITS ASSEMBLING CONCEPTS AS A METHODOLOGICAL TOOL FOR VISUAL RESEARCH.}

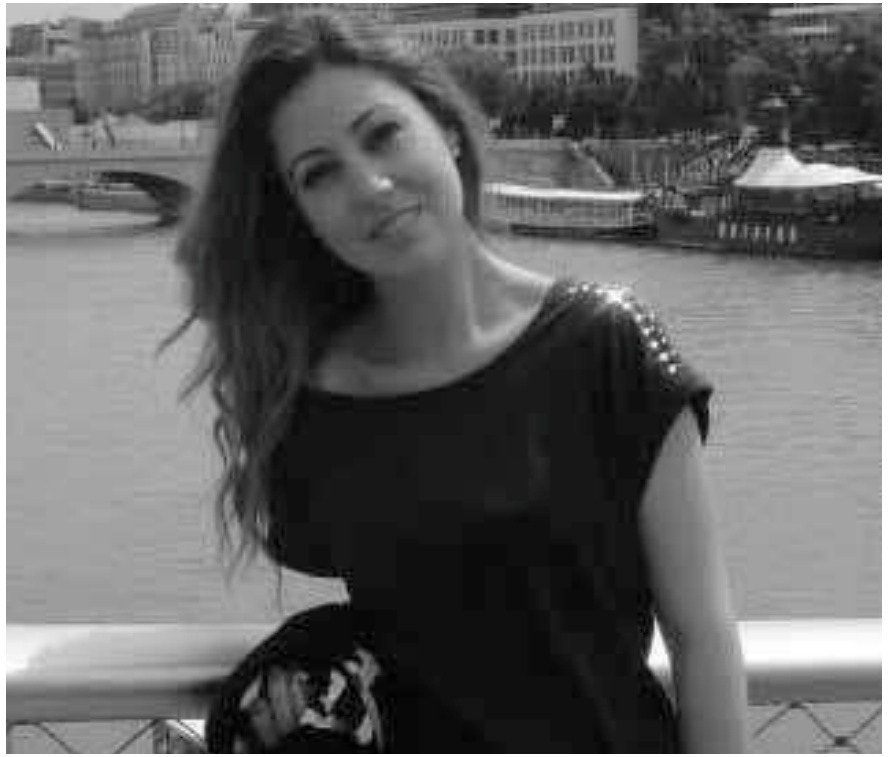

\section{Daniela Queiroz Campos}

Doutora - Universidade Federal de Santa Catarina Pós-doutoranda - CETHA/EHESS

Centre d'histoire et théorie de l'art et des images Écoles des Hautes Études en Sciences Sociales/ Paris

camposdanielaqueiroz@gmail.com

\section{RESUMO}

O presente estudo visa propor um método visual para o design. Dentro o escopo tecnológico para o projeto de design o painel semântico alcança grande e quase que irrestrita utilização. A aplicabilidade de métodos visuais na construção de produtos visuais assinala-se sua suma importância na estimulação e na inspiração no decorrer da fase projetual. O chamado Atlas 
Mnemosyne fora proposto por Aby Warburg como um quadro associativo de imagens. A metodologia visual proposta pelo projeto embasa-se principalmente em uma ferramenta - o Atlas - que auxiliaria na prática projetual do design. Grosso modo, o Atlas Mnemosyne se assemelharia ao já bastante utilizado na área do design painel semântico. Contudo, o Altas adicionaria a esse painel, principalmente, o caráter de renovação. $O$ painel semântico a partir do momento em que é postulado, não pretende ser alterado ao longo de todo o processo projetual. O Atlas, por sua vez, apresenta-se como ferramenta aberta; a associação de imagens nele proposta pode, e busca, ser constantemente feita e refeita. Assim, novas referências e requisitos podem renovar o processo projetual no decorrer de seu desenvolvimento.

\section{PALAVRAS-CHAVE}

Design. Pesquisa Visual. Imagem. Atlas. Mnemosyne.

\section{ABSTRACT}

The present study aims to propose a visual method for design. Within the technological scope of the design project, the semantic panel reaches a great - almost unrestricted use. The applicability of visual method in the construction of visual products stresses the substantial importance for inspiration and stimulation throughout the design (projecting) phase. The so-called Atlas Mnemosyne was proposed by Aby Warburg as a associative image canvas. The visual methodology proposed by this project is primarily grounded on a tool - the Atlas - that would assist the project praxis in the field of design. Roughly speaking, the Atlas Mnemosyne resembles the semantic panel, already widely used in the area of design. However, the Atlas would add to such panel, especially, the renewal characteristic. The semantic panel, after assembled, is not intended to be changed at all throughout the design process. The Atlas, on the other hand, presents itself as an open tool. The images assemble proposes - and seeks - to be constantly made and remade. Thus, new references and requirements may renew the design process in the course of its development. 


\section{KEYWORDS}

Design. Visual Search. Image. Atlas. Mnemosyne.

\section{A PESQUISA VISUAL COMO MÉTODO}

O design enquanto campo de conhecimento tem suas contribuições sociais voltadas à configuração e a estruturação de interfaces de artefatos, sejam eles materiais ou visuais-semióticos e digitais (BONSIEPE, 2011). No desenvolvimento de produtos de design, o trabalhar com imagens, com os pela área chamados métodos visuais, vem paulatinamente tornando-se um imperativo (GUSMÃO, 2012). Os métodos de pesquisa utilizados tanto pelos pesquisadores e professores quantos pelos profissionais da área para a realização dos projetos em design são distintos. Entre os muitos métodos de pesquisa utilizados, para o recorte proposto, aqui destaco e sublinho o método de pesquisa visual.

Para Noble e Bestley os métodos de pesquisa em design podem ser definidos tanto como modos de aproximação de problemas de design, quanto como investigação de contextos para a atividade (NOBLE, BESTLEY, 2011). Estes métodos podem auxiliar o designer a fazer uso mais eficiente de suas descobertas e trabalhem de maneira mais prática e criativa em contexto cultural amplificado. Dentro deste vasto escopo metodológico projetual do design, figuram-se os métodos visuais. Na pesquisa metodológica visual, o design utiliza-se sobremaneira de uma ferramenta de pesquisa específica: o painel semântico. Este é utilizado como técnica metodológica na concepção projetual do design. Entretanto a concepção do painel semântico no contexto da atividade projetual de design, na academia e no mercado, proposta por Baxter (1998) não tem sido consistentemente revisada pelos teóricos da área. No decorrer das últimas décadas o campo do design é atingido por transformações culturais, sociais e tecnológicas que remodelaram o próprio fazer design.

Frente a tal panorama, o presente projeto propõe uma outra ferramenta metodológica, que tal qual o painel semântico, também seria utilizada como subsídio às escolhas e pesquisas imagéticas no campo do design. A ferramenta metodológica proposta alia-se às correntes teóricas e epistemológicas mais contemporâneas nas áreas de filosofia, antropologia, artes, letras, comunicação e propõe a renovação urgente da 
ainda tradicional abordagem imagética do design.

\section{MNEMOSYNE E ABY WARBURG}

No campo de conhecimento da história da arte, um Atlas imagético foi proposto pelo renomado estudioso alemão Aby Warburg. O Atlas foi denominado pelo seu próprio mentor de Atlas Mnemosyne. Warburg, historiador da arte do final do século XIX e do início do século XX, propôs uma composição, uma montagem de imagens a partir de relações associativas (Didi-Huberman, 2013a). Essas associações imagéticas são propostas como um processo ou um método sempre em movimento; ou seja, as associações das imagens não são fixas, rijas, imóveis, tal como ocorre com o painel semântico. A associação de imagens como proposta por Aby Warburg marca-se pelo seu caráter de renovação, inovação; caráter esse tão caro a atividade projetual do design.

Foram vários os estudioso dos campos da teoria da arte, da história da arte, da filosofia, das letras e da história que se dedicaram aos estudos de Aby Warburg. Entre a vasta contribuição do historiador da arte alemão, 0 Atlas Memosyne destaca-se sobremaneira na atualidade. Nenhum dos muitos comentadores de Warburg deixou de tecer análise sobre o considerado último grande trabalho do estudioso.

Georges Didi-Huberman é considerado um dos principais discípulo de Aby Warburg. O contemporâneo filósofo Didi-Huberman destaca-se na área de antropologia visual, já tendo publicado mais de 50 livros cujas temáticas abordam a imagem. $\mathrm{O}$ atual mestre de conferências da École des Hautes Etudes en Sciences Socieles [1] aborda a imagem na sua amplitude. Tanto na concepção da sua criação, quanto da sua recepção. O Atlas é visto por ele como método fecundo e fundamental para lidar com a problemática imagética. Tal estudioso fez a curadoria de várias exposições chamadas Atlas em conceituados museus como o Reina Sofia (na cidade de Madri, Espanha), o Museu do Mar (na cidade do Rio de Janeiro, Brasil) e no Palais de Tokio (na cidade de Paris, França).

\section{O ATLAS E O PAINEL SEMÂNTICO}

O nome Atlas remota à Grécia Antiga. A palavra grega 'A $\tau \lambda \alpha \varsigma$ significa 
aquele que sustenta a abobada celeste (BRANDÃO, 2008). Bem antes de referir-se a uma espécie de compilação de imagens, a palavra designava 0 nome de um titã. De acordo com a mitologia grega, Atlas juntamente a seu irmão Prometeu pretendia enfrentar os deuses do Olimpo. Ao enfrentar tais deuses, eles almejavam assimilar seus poderes para então dá-los aos homens. Como tal investida fracassou, os irmãos foram condenados na mesma medida de sua fraqueza. Atlas foi condenado a carregar em suas costas o peso do mundo. Mais tarde, no século XVI, o termo foi utilizado para a designação de um códice composto por uma espécie de organização e compilação de conhecimentos geográficos e astronômicos (BUCHLOH, 1999). O nome Atlas estaria estreitamente relacionado com a coleção de mapas de um mercador do final do XVI. Apenas no final do século XVIII e no início XIX o termo teve sua utilização ampliada para designar apresentações tabelares de conhecimento sistemático. O Atlas cumprira então com a sentença que lhe fora dada - ele carregava o mundo nas costas. Fora, deste modo, utilizado para designar estas apresentações tabelares de conhecimento sistemático. O Altas aqui proposto como ferramenta na metodologia da pesquisa visual em design pretende apresentar e organizar de forma sistemática as imagens como referenciais coletados que auxiliam na prática do design.

O fazer design, é de certa forma, um fazer projetual. No decorrer desse processo projetual, os profissionais envolvidos percorrem inúmeras etapas, dentre elas a etapa de criação. Atualmente o uso do painel semântico visa organizar as imagens referenciais coletadas no início da elaboração do projeto criativo - na etapa de conceituação. Neste painel são colocadas inúmeras imagens que abarquem ou que traduzam uma linguagem verbal, ou seja, o conceito do projeto que muitas vezes é metafórico ou abstrato é transformado em imagens referenciais (GUSMÃO, 2012). De tal feita, ele pode ser considerado um agente de criação e mediação no âmbito projetual. Diversos aspectos do projeto são divididos em grupos e organizados visualmente em alguns painéis; cada um contemplando um destes grupos em questão, que costumeiramente são repartidos em objetos, pessoas e ambientes.

Esses painéis repletos de imagens referenciais do projeto são utilizados em inúmeras fases de criação. Dos painéis são retirados conceitos subjetivos e elementos imagéticos. O público alvo do produto do design está nele expresso desde em elementos mais subjetivos como em metáforas, símbolos, 
estilos de vida até em subsídios mais pontuais como formas, cores, texturas e tipografias (FACCA, 2012).

Segundo a literatura da área, esse painel pode ser desenvolvido em etapas. Jacques e Santos (2009) postulam seu desenvolvimento em cinco. A primeira delas consiste na compreensão do problema do projeto, a segunda objetiva a transformação do problema em conceitos verbais, cunhando o termo brainwriting. Em seguida, a terceira etapa implica na transformação da linguagem escrita em imagem, a quarta etapa propõe a montagem do painel e a quinta e última etapa intenta definir uma cartela de cores, formas e texturas direcionadas a aplicação em produto.

A principal crítica levantada às cinco etapas propostas pelos autores é que o painel semântico limita-se apenas à terceira e à quarta etapas, onde há a seleção e a montagem das imagens em um painel. As demais etapas têm relação com o painel semântico, mas não consistem na construção do mesmo. São processos anteriores e posteriores à sua elaboração.

Já Edward, Fadzli e Setchi (2009) elaboram um diagrama que contém as etapas do processo de criação do painel semântico, sendo elas: coleta de imagem, seleção de imagens, organização das imagens, período de reflexão. O diagrama proposto pelos estudiosos apresenta a criação do painel como processo cíclico, contudo uma vez elaborado, o painel semântico não poderia sofrer alterações. Sendo assim, mesmo o processo sendo cíclico, seu resultado seria final, não sofrendo alterações após considerado pronto.

O fechamento conclusivo de painel impossibilita a inserção de novas imagens, ideias e conceitos no decorrer do processo projetual. Por exemplo, no caso do designer deparar-se com uma imagem relevante ao projeto após o fechamento do painel ele não poderia incluí-la. Um outro exemplo seria em projetos de longa duração em que as tendências de mercado e as capacidades tecnológicas são velozmente renovadas e podem - irão influir nos resultados.

Edward, Fadzli e Setchi ainda pontuam as subjetividades como prejudiciais ao processo, colocam as diferenças educacionais e culturais do sujeito como um ponto negativo da técnica. "A experiência pessoal e a inspiração do criador do painel semântico levanta uma questão relacionada com a abstração extrema, o que poderia afetar a eficácia do painel semântico" (EDWARD, FADZLI, SETCHI, 2009, p.6).

Em favor dos autores, a objetividade do processo provavelmente o 
torna mais eficiente, pois minimizaria a margem de erro na seleção arbitrária de imagens. Contudo, o mais eficiente não necessariamente garante a eficácia dos resultados. Em projetos para inovação é mais interessante a utilização de referências poucos convencionais, como postula Raymond (2010) em favor das anomalias. Para o pesquisador inglês ideias inovadoras surgem às margens. À margem faz a interface entre o que é interno e externo à cultura. A margem é parte de dentro, mas conecta-se com o que é de fora. Traz referência externas que podem ser assimiladas pela cultura interna. Novidades que transformam-se em inovação.

\section{O ATLAS COMO UMA PROPOSTA INOVAÇÃO}

A proposta do Atlas contribuirá para a eficiência em inovação almejada. Um dos principais pontos de divergência com o painel semântico é sua possibilidade e sua intencionalidade de mudança ao longo do projeto. As imagens postas no Atlas não têm posição fixa, podem movimentar-se na superfície de cada prancha bem como sair ou entrar nela. O Atlas não consiste em um único painel, mas em um coletivo de pranchas, cada qual contendo um número indeterminado de imagens. Cada prancha tem uma organização imagética temática que se conecta ou não com as demais. A ideia de Warburg com o Atlas era estabelecer elos imagéticos jamais fixos (DIDI-HUBERMAN, 2014).

O Atlas Mnemosyne foi o último grande projeto desenvolvido pelo renomado historiador da arte alemão Aby Warburg (MICHAUD, 2013). Para Giorgio Agamben (2008), Warburg modificou todo o trabalhar e o pensar com imagens. $\mathrm{O}$ alemão transformou o modo de compreender as imagens, já que incorporou questões radicalmente novas para sua compreensão.

O Atlas Mnemosyne era composto por diversos paineis - na época, telas de madeira cobertas por tecido preto. Sobre tais tecidos eram fixadas imagens e textos - cópias de quadros, reproduções fotográficas, pedaços de periódicos - organizados a partir de eixos temáticos. A multiplicidade da natureza das fontes utilizadas em seu Atlas e em suas pesquisas é questão latente da obra de Warburg. Questão que faz com que ainda hoje seja difícil falar de imagem, sem tocar em seu nome, ou em um dos nomes daqueles tantos que o seguiram.

Os painéis móveis que compunham o Atlas foram montados em 
outra obra empreendida por Warburg: a Biblioteca de Ciência da Cultura -Kulturwissenschaftliche Bibliothek Warburg. Ainda durante a vida do historiador, a Biblioteca de transformou-se em um instituto - o Instituto Warburg; inicialmente construído na cidade alemã de Hamburgo e por razões das políticas nazistas transladado para a cidade de Londres. Aby Warburg deixou como legado suas obras, sua biblioteca, seu instituto e principalmente muitos nomes que continuaram a trabalhar a partir de sua perspectiva. Para Carlo Ginzburg (2007) e José Emílio Burúcua (2010), o espólio de Warburg ultrapassa o recém mencionado, ele inaugura um método (GINZBURG, 2007). Já para Giorgio Agamben, o legado de Warburg consiste em uma ciência.

O método é altamente reconhecido na contemporaneidade. Muitos são os pesquisadores considerados os herdeiros de Aby Warburg, dentre eles o já mencionado Georges Didi-Huberman. Para o filósofo francês uma das principais inovações do Atlas é a subjetividade implicada na montagem das imagens propostas. Se para Edward as experiências individuais do criador são negativas para a técnica, para Didi-Huberman ela traria a própria potência e a criatividade ao método.

Ao escrever sobre o Atlas, Didi-Huberman utiliza-se do termo montagem. Na construção das pranchas e do próprio Atlas, as imagens devem ser montadas com base nas semelhanças. Didi-Huberman utilizase de Walter Benjamin e de sua "doutrina da semelhança" como aparato. A partir delas, pode-se construir uma montagem de diferentes imagens que, por semelhança, tocam-se. Montagem que nos permite perceber multiplicidades e singularidades através das imagens.

Aby Warburg, na elaboração de seu Atlas Mnemosyne, teria alcançado este conhecimento sobre a montagem ao organizar em 79 pranchas imagens dos mais diferentes tipos que foram montadas e encaixadas mediante escolhas. Fotografias de Roma, afrescos de Rafael, xilogravuras anti-semitas, imagens esportivas. O embaralhar de cartas, este jogo de associações, estes dados contingentes (DIDI-HUBERMAN, 2012). Estas articulações montadas produzem efeito sobre nosso conhecimento inteligível. As aproximações de diferentes tipos de imagens, de algum modo, produzem modificações. Uma espécie de abertura em nosso olhar (DIDI-HUBERMAN, 2011) que podem contribuir para o surgimento do novo.

"Ce sont les montages sensibles que servent souvent à poser de nouvelles 
d'intelligibilité" [2]. Montagens sensíveis que nos colocam diante de uma nova inteligibilidade, novas obras, novos ritmos, nova visibilidade, novas imagens, novas montagens. Didi-Huberman entende o Atlas como forma visual de conhecimento[3]. O que o historiador da arte alemão propunha era uma nova maneira de pensar através de um método de montagem de imagens.

Podemos aproximar o trabalho de montagem elaborado por Aby Warburg em seu Atlas Mnemosyne com o Livro das Passagens escrito por Walter Benjamin (2002). Neste, onde Benjamin estabelece seus pensamentos em trechos, também existe uma certa forma de montagem. São escritos sobre uma diversidade temáticas que aludem à Modernidade. Excertos fragmentados que, todavia, compõem uma grande imagem. Uma montagem que constrói conhecimento.

Este "conhecimento-montagem", estabelecido por Aby Warburg e ensaiado por Walter Benjamin em seu Livro das Passagens, inaugura uma nova forma de apresentar imagens. Uma multiplicidade de coisas reunidas por afinidades eletivas seria o amálgama de ambos os trabalhos. As imagens montadas por Warburg em seu Atlas e os textos escritos e montados por Benjamin em suas Passagens. Esta multiplicidade, fruto das montagens, tem sido exploradas por pesquisadores e artistas, mas podem, sobremaneira, contribuir para outras áreas do conhecimento como método ou como ferramenta metodológica.

\section{O ATLAS MNEMOSYNE COMO FERRAMENTA METODOLÓGICA}

O Atlas Mnemosyne, de Aby Warburg, está aqui sendo proposto como uma ferramenta metodológica que auxilie o projeto de design[4]. A presente posposta trata-se de um pos-doutoramento que vem sendo realizado no Centro de história e de teoria da arte e das imagens na École des Hautes Études en Sciences Socieles de Paris Atlas que já fora intensamente trabalhado e analisado por várias áreas de conhecimento, pode ser proposto para o âmbito projetual de design dada suas características de criatividade e de inovação através dos critérios da subjetividade e da flexibilidade da imagem O Atlas convida profissionais e estudantes de design a pensar através de imagens, uma vez que ele não se trata de um "resumo de imagens", mas 
de um próprio pensamento por imagens. Cabe ao designer ver no Atlas uma estrutura visual de todo o seu pensamento.

Mnemosyne era, antes de qualquer coisa, uma disposição fotográfica. Num primeiro momento, essas impressões fotográficas foram agrupadas por temas, coladas em grandes de papelão e agrupadas em um espaço elíptico em umas das salas da Kulturwissenschaftliche Bibliothek Warburg. Contudo, fixar as imagens com cola em papel as tirava o movimento e o caráter de mudança. De tal feita, Warburg começou a manipular tais imagens de forma diferente. Foram montadas grandes placas de tecido negro em formato retangular de um metro por dois metros e meio. Nessas placas, a imagens não eram mais coladas, mas fixadas através de prendedores.

O método visual propõe imagens nunca fixas, já que Warburg renuncia fixar imagens. "Warburg havia compreendido que devia renunciar a fixar imagens, assim como um filósofo precisa saber renunciar a fixar suas opiniões" (DIDI-HUBERMAN, 2013. p.389). Propôs-se um pensamento em seu caráter de mudança. A cola fora abandonada em função do grampo - que sempre pode permutar, sempre pode prende algo diferente; possibilita um jogo que nunca tem um fim, mas várias etapas. Cada uma das composições imagéticas feitas por Warburg em cada uma dessas pranchas eram registradas fotograficamente.

Esse protocolo experimental é bastante interessante para a atividade projetual do design. Obviamente não venho propor que o designer passe a prender imagens com grampos e uma prancha coberta por tecido negro. Sugiro a composição de paineis, seguindo uma forma de comparativismo e de montagem, que não fosse fechada nem terminada ao longo de todo o trabalho projetual. A composição do Atlas funcionaria através da montagem de pranchas, paineis, que acomodariam imagens que referenciassem público alvo, estilos de vida, cartelas de cores, texturas, tipografias, formas, etc. Essas pranchas seriam montadas através de associações imagéticas.

O Atlas poderia ser desenvolvido em quatro etapas: pensar imagens, montar pranchas, registrar pranchas e remontar pranchas. O Atlas seria composto por essas pranchas que ao longo de todo o processo projetual poderiam, e deveriam, sofrer modificações. Cada uma das etapas desses paineis seriam registrados e no final do processo comparadas, analisadas e discutidas. Os paineis seriam experimentados no mesmo processo projetual do produto. 
Lembro que o projeto é um dos mais importantes valores do Atlas Mnemosyne, um projeto sempre aberto e experimental que não reduz a diversidade a uma unidade. Ele propõe-se um método de desdobramento. $O$ caráter de experimentalidade do Altas adiciona caráter inovador ao acumular referências pouco convencionais ao design. Aqui as anomalias de Raymond (2010) vêm das artes e de sua história. Vêm de um historiador da arte que modifica de forma abrangente o trabalhar imagem e que cada vez mais vem sendo retomado por pensadores da contemporaneidade.

\section{NOTAS}

[1] A École des Hautes Études en Sciences Sociales (Escola de Estudos Avançados em Ciências Sociais) ou EHESS é uma instituição francesa de ensino superior e pesquisa em ciências sociais do tipo grand établissement (grande estabelecimento), isto é, um estabelecimento público de caráter científico, cultural e profissional voltado para o ensino superior (essencialmente de pós-graduação) e a pesquisa. É um dos mais prestigiosos estabelecimentos de ensino superior e pesquisa em ciências sociais, oferecendo as seguintes áreas de especialização: história, linguística, filosofia, filologia, sociologia, antropologia, economia, ciencia cognitiva, demografia, geografia, arqueologia, psicologia, direito e matemática - embora a prioridade da instituição seja a pesquisa interdisciplinar nesses campos.

[2] Estás são montagens sensíveis que servem, com frequência, para se colocarem novas inteligibilidades (tradução nossa) DIDI-HUBERMAN, G. L'image survivante. Histoire de l'art et temps des fantômees selon Aby Warburg. Paris: Minuit, 2002.

[3] DIDI-HUBERMAN. L'image survivante. Histoire de l'art et temps des fantômees selon Aby Warburg. Paris: Minuit, 2002.

[4] O presente trabalho faz parte de um pós-doutorado realizado no CETHA (Centro de história e teoria da arte e das imagens) da EHESS (École des Hautes Études en Sciences Sociales) de Paris sob a supervisão do Professor Georges Didi-Huberman e contemplado com uma bolsa pelo programa de financiamento Ciências Sem Fronteiras do CNPq. 


\section{BIBLIOGRAFIA}

$B E S T L E Y, R ; N O B L E$, lan. Introdução às metodologias de pesquisa em design gráfico. Porto Alegre: Bookman, 2013.

BONSIEPE, G. Design, Cultura e Sociedade. São Paulo: Blucher, 2011.

BUCHLOH, B. Gerhard Richter's Atlas: the anomic archive. In: Photography and painting in the work of Gerhard Richt. Barcelona: LibresRecerca Arte 6, 1999.1130.

BURDEK, B. E. Design: The History, Theory and Practice of Product Design. Basel: Birkhauser, 2005.

BURUCÚA, J. E. História, arte, cultura: De Aby Warburg a Carlo Ginzburg. Buenos Aires: Fondo de Cultura Econômica, 2007.

COELHO, L. A. L. (org). Design Método. Rio de Janeiro: Ed. PUC-RIO; Teresopolis: Novas Ideias, 2006.

DIDI-HUBERMAN, G. A imagem sobrevivente. História da arte e tempo dos fantasmas segundo Aby Warburg. Editora Contraponto, 2013.

. Ante la imagen. Pregunta formulada a los fines de una historia del arte. Madrid: Ediciones Cedeac, 2010.

A pintura encarnada e Honoré Balzac. A obraprima desconhecida. Tradução de Osvaldo Fontes e Leila de Aguiar Costa. São Paulo: Escuta, 2012.

Atlas: como levar el mundo a cuestas? Texto de apresentação escrito por Georges Didi-Huberman no floolder da exposição homônima realizada no Museu Reina Sofia, Madri, Março de 2011.

. Blancs soucis. Paris: Minuit, 2013.

2013.

. Cascas. Revista Serrote, São Paulo,.n.13 p.99-131.

de l'art. Paris: Minuit, 1990.

Devant l'image. Question posée aux fins d'histoire

Imagens pense a todo: memoria visual del Holocausto. Barcelona: Ediciones Paidós Ibérica, 2004.

Politécnica de Valencia, 2007.

La pintura encarnada. Valencia: Universidad

La ressermblance par contact. Archéologie, anachronisme et modernité de l'empreinte. Paris : Les Éditions Minuit, 2008. 
Las condition des images par Didi-Huberman. IN: AUGÉ, Marc; DIDI-HUBERMAN, Georges; ECO, Umberto. L'experience des images. Paris: L'eu editions, 2011.

Pompidou, 1997. L'empreinte. Paris: Éditions Du Centre Georges

L'image survivante. Histoire de l'art rt temps des fantômees selon Aby Warburg. Paris: Minuit, 2002.

Ediciones Manantial, 2006.

Lo que vemos, lo que nos mira. Buenos Aires:

Ninfa Moderna. Essai sur le drapé tombé. Paris:

Gallimard, 2008.

Ouvrir Venus. Nudité, rêve, cruauté. Paris: Éditions

Gallimard, 1999.

O que vemos, o que nos olha. São Paulo: Editora 34,

2010.

Sobrevivência dos vaga-lumes. Belo Horizonte:

Editora UFMG, 2011. P.119.

. Venus rajada. Buenos Aires: Editorial Losada,

2005.

EDWARD, A.; FADZLI, S.; SETCHI, R. Comparative study of developing physical and digital mood boards. Anais.... $5^{\text {th }}$ International Conference on Innovative Production Machines and Systems. Carfiff, UK, 2009.

FACCA, C. O designer como pesquisador: uma abordagem metodológica da pesquisa aplicada ao design de produtos. Dissertação de Mestrado. Universidade Anhembi Morumbi, São Paulo, 2008.

MELENDI, M. A. A solidez do arquivo: Entre pedras soterradas e fotografias esquecidas. IN: FLORES, Bernardete Ramos e VILELA, Ana Lúcia (orgs.). Encantos da Imagem: Estâncias para a prática historiográfica entre história e arte. Blumenau: Letras Contemporâneas, 2010.

GINZBURG, C. De Warburg a E. H. Gombrich: notas de um problema de método. In: Mitos, Emblemas, Sinais: Morfologia e História. São Paulo: Companhia das Letras,

JACQUES, J. J.; SANTOS, R. F. do. O Painel Semântico como Ferramenta no Desenvolvimento de Produtos. Anais V CIPED, Bauru, p.531-538, 2009. Disponível em: http://www.academia.edu/3507288/Painel_Sem\%C3\%A2ntico_ como_t\%C3\%A9cnica_metodol\%C3\%B3gica_no_ensino_da_pr\%C3\%A1tica_ projetual_em_design 
WARBURG, A. Atlas Mnemosyne. Madrid: Impresos Cofás S.A. 2010.

A renovação da Antiguidade pagã. Contribuições científicoculturais para a história do Renascimento europeu. Rio de Janeiro: Editora Contraponto, 2013.

- Imagens da região dos índios pueblos na América o Norte. IN: Revista Concinnitas: artes, cultura e pensamento. Rio de Janiero, a. 6, v. 1, n. 8, p. 110, 130. 2005.

El Renacimiento del paganismo. Aportaciones a la historia cultural del Renacimiento europeo. Madrid: Alianza Editorial, 2005.

Recebido em: 10/04/2014; Aceito em: 12/04/2014.

Esta obra foi licenciada com uma Licença Creative Commons.
Daniela Queiroz Campos é pesquisadora junto à Ėcole des Hautes Ėtudes en Sciences Sociales de Paris sub a supervisão do Professor Doutor Georges Didi-Huberman. Desenvolve uma investigação pós-doutoral acerca do Atlas Mnemosyne aplicado ao design com o financiamento do Ciências sem Fronteiras, Cnpq. É Doutora em História pela Universidade Federal de Santa Catarina tendo realizado estágio doutoral na EHESS, mestre em História Pontifícia Universidade Católica do Rio Grande do Sul e graduada em História pela Universidade do Estado de Santa Catarina. 